\title{
Directo e local nunca mais? As comunidades de ouvintes e as tendências de globalização na propriedade e produção de rádios locais
}

Guy Starkey*

Resumo: Este artigo considera a tendência que se regista no Reino Unido e noutros lugares do mundo para que estações comerciais de rádio de propriedade local, de criação local e de gestão local caiam nas mãos de grupos nacionais e até internacionais de média que colocam em situação desvantajosa as comunidades das quais eles procuram colher lucro, ao remover delas um meio de expressão cultural. No essencial, o sentido de localidade na rádio local é uma espécie em vias de extinção, embora seja um fenómeno relativamente recente. Uma regulação mais ligeira tem significado também uma crescente automatização, pelo que a própria apresentação em directo está sob ameaça. Traçando o desenvolvimento inicial da rádio local, através de debates ideologicamente contaminados em torno do serviço público de radiodifusão e da aptidão do sector privado para explorar recursos escassos, até aos ambientes digitais actuais nos quais as razões tradicionais para a regulação da propriedade e do conteúdo se têm tornado cada vez mais desafiadas, o artigo também especula sobre futuros desenvolvimentos na rádio local.

Palavras-chave: rádio, local, serviço público de radiodifusão, rádio comercial, comunidade.

\section{Introdução}

O âmbito deste artigo é imenso, porque requer algum estudo histórico, bem como alguma reflexão sobre a actualidade. Ele concerne principalmente aos desenvolvimentos de mais de noventa anos num país, o Reino Unido, e ainda se refere a um fenómeno observado numa grande variedade de outros países na Europa e não só. Este fenómeno é o que tem as suas origens na década de 1920, mas que se tornou mais evidente nos últimos 25 anos, uma vez que as expectativas institucionais e do público sobre a importância e a adequação da regulamentação mudaram ao longo do tempo. Tal mudança foi inspirada

* Professor na University of Sunderland, Inglaterra (guy.starkey@sunderland.ac.uk). 
por outros fenómenos, enraizados em aspectos da economia política, nas mudanças sociais e também nos desenvolvimentos na cultura popular, cada um dos quais podendo ter sido influenciado por sua vez pelos avanços tecnológicos. Estes últimos podem ter sido o mais decisivo agente catalisador para a mudança, simplesmente por causa das novas oportunidades e desafios que trouxeram aos processos de mediatização e porque o avanço tecnológico nas indústrias de média tem sido exponencial. O ritmo com que a tecnologia tem influenciado os contextos mais vastos em que é implantada acelerou-se na nossa história mais recente. No seu coração é um paradigma conhecido como "globalização". Admitindo que a globalização vai aumentar em importância, ao invés de diminuir, muitos comentadores assumem que ela tem um potencial considerável para danificar a independência económica dos Estados, regiões e comunidades locais, para enfraquecer a identidade nacional, para corroer o património e o desenvolvimento culturais e para ameaçar a autonomia política das minorias grandes e pequenas.

Apesar da insistência, em 1964, do estudioso canadiano Marshall McLuhan de que a encolhida "aldeia global" do já substancialmente mediatizado mundo não era uma influência homogeneizante sobre as sociedades (2001: 334), pode-se argumentar, mais ou menos convincentemente, que uma mudança significativa tem ocorrido desde 1964 e, com a subsequente aceleração do ritmo das mudanças, tanto tecnológicas como sociais, a ameaça da globalização cresceu. O fenómeno da globalização que é central para este artigo é este: a diminuição do sentido de localidade dos conteúdos e da propriedade na radiodifusão. A rádio local foi crescendo em importância na viragem do último milénio, mas desde então tem entrado em declínio devido a factores relacionados com a economia política dos meios de comunicação de massa - e isso pode ser de grande importância num mundo cada vez mais sujeito às forças da globalização.

Esta tendência pode ser generalizável para muitos territórios do mundo. A diminuição do sentido de localidade está a ocorrer de várias maneiras, mas na sua essência pode ser racionalizada no facto de estações de rádio comerciais de propriedade local, de origem local e de gestão local estarem a cair no controlo de grupos nacionais e até internacionais de média, que colocam em situação desvantajosa as comunidades das quais procuram obter lucro, delas removendo um meio de expressão cultural e de participação democrática. Meios de comunicação de pequena escala controlados pelos cidadãos locais podem dar voz às minorias e às maiorias, dar poder aos grupos e indivíduos que, de outro modo, seriam marginalizados por grandes corporações de média e emissoras nacionais. Os média locais têm o potencial de unir as comunidades através das suas características comuns e de aumentar as expectativas de acesso entre os indivíduos em relação às estruturas e processos democráticos locais e regionais. Subjacente a este apoio à democracia, os média locais (incluindo a rádio local) podem reflectir e incentivar a diversidade cultural no seio de populações pequenas e grandes. Há muitos exemplos de rádios que reflectem e encorajam a diversidade cultural no seio de populações pequenas e grandes e, por isso, seria errado, especialmente no Reino Unido, afirmar que a cultura popular, que é predominantemente local ou regional por natureza, pode estar sujeita a variações locais que têm o potencial de ser encorajadas e reflectidas nos meios de comunicação de propriedade e origem local tais como a rádio. 


\section{0 nascimento e a morte antecipada da rádio regional}

Porque em 1927 a BBC era um órgão estatal que beneficiou de um estatuto privilegiado, era expectável que fornecesse ao seu público determinados níveis de serviço de uma qualidade que, pensava-se, as empresas privadas dadas ao lucro não poderiam fornecer. Em troca, seria financiada a partir de uma taxa de licença paga por todos os que tinham um receptor sem fio. Este foi o nascimento da noção de serviço público de radiodifusão, mas era bastante diferente do modelo americano, em que a radiodifusão estava entregue sobretudo à iniciativa privada. Nos EUA não havia taxa de licença nem monopólio de nenhum organismo de radiodifusão, mas as estações de rádio podiam ser criadas por empresas privadas ou indivíduos, a fim de gerarem lucro através da cobrança a outras empresas pela publicidade. O que pode ter parecido a anarquia para os britânicos era na verdade muito bem organizado, porque as estações eram licenciadas por um regulador (um número de diferentes organismos desempenhou este papel, que a partir de 1934 foi realizado pela Comissão Federal de Comunicações ou FCC). Esta divergência identifica mais do que duas indústrias de rádio muito diferentes. As decisões tomadas pelos legisladores criaram uma divisão ideológica entre os mercados livres em alta nos EUA, que acreditavam que o mercado prestaria o serviço de transmissão que o povo queria, e os defensores do serviço público de radiodifusão no Reino Unido, que acreditavam firmemente que não se poderia confiar no mercado para fornecer o que seria considerado bom para o povo. O modelo britânico, prontamente adoptado de uma forma ou de outra (Starkey, 2007: 23) por alguns países europeus, foi claramente contrário, do ponto de vista ideológico, ao capitalismo completamente livre.

No Reino Unido, como em outros lugares, a rádio cedo se desenvolveu numa base local, ou pelo menos regional. Em 1920 os Correios deram permissão à Companhia Marconi para transmitir de forma intermitente para um pequeno número de entusiastas da rádio a partir de um transmissor de baixa potência no condado de Essex, usando o sinal de chamada 2MT. Em 1922, a isto seguiu-se uma licença formal para regularmente transmitir um serviço de Londres, 2LO. Outras estações passaram a estar no ar em Birmingham, Manchester, Newcastle, Cardiff, Glasgow, Aberdeen, Bournemouth, Sheffield, Plymouth e Belfast, cada uma com os seus próprios sinais de chamada com os quais se identificavam no ar. Além disso, havia transmissores de serviços vizinhos em Edimburgo, Liverpool, Leeds e Bradford, Hull, Nottingham, Dundee, Stoke-on-Trent e Swansea (McCarthy, 2007: 1-9). As estações transmissoras, onde havia financiamento considerado insuficiente ou a necessidade de criar um serviço personalizado, forneceram um dos primeiros exemplos de como uma área geográfica podia ter a sua rádio própria, simplesmente estendendo outra além da sua zona de transmissão original. A engenharia tecnológica não poderia apoiar o uso limitado de transmissões, que dependia da agregação em conjunto de várias linhas telefónicas. A abertura de uma estação de alta potência em banda larga de frequências trouxe consigo o novo conceito de serviço nacional. As históricas Asa Brings da BBC relatam em detalhe como o novo serviço de banda larga, sinal de chamada-5XX, ficou conhecido como o Programa Nacional. Isto aconteceu em paralelo com o novo sinal de chamada genérico, do Programa Regional, uma vez que as estações regionais originais perderam os seus sinais de chamada originais. A oferta 
resultante significava que os ouvintes nas partes mais populosas do Reino Unido tinham uma escolha de dois serviços de rádio: um nacional e outro baseado nas suas próprias regiões (Briggs, 1961). Este novo serviço nacional de banda larga nasceu da preocupação de que haveria muito poucas frequências disponíveis para fornecer suficientes serviços regionais separados ou mesmo transmissores de serviços para cobrir todo o país.

O que aconteceu depois do início da história da rádio do Reino Unido é um precursor claro de alguns dos acontecimentos mais recentes do princípio do século XXI. Este é um fenómeno que se deve referir como "consolidação". Concentrar os recursos do que se tornou a BBC numa programação de um número menor de estações individuais fazia sentido económico, e o período até à Segunda Guerra Mundial tornou-se de consolidação. As diferenças regionais entre o 'opt-outs' [regras de envio] nas redes de emissoras do Programa Regional diminuíram gradualmente até à eclosão da guerra total, mas acabaram com a radiodifusão regional, pelo menos por um tempo. Em 1939, os Programas Nacionais e Regionais foram suspensos, para serem substituídos pelo BBC Home Service, um novo sinal de chamada e marca que estava a ser transmitido há mais de 28 anos. Após a guerra, emergiram as variações regionais do Home Service (escocês, do Norte, Midland, de Gales, Oeste e da Irlanda do Norte), assim como um serviço de entretenimento novo, The Light Programme (1945-1967) e o 'intelectual' Third Programme (1946-1967) (Crisell, 1994: 22, 24-5). No entanto, estes eram meros abandonados da programação nacional do Home Service, e assim no Reino Unido até ao final do primeiro meio-século da rádio, a clara preferência por um sistema de transmissão baseado em serviços nacionais tinha sido firmemente estabelecida.

\section{Desafios ao monopólio da BBC}

O potencial da rádio como meio de publicidade para fazer com que os empresários ganhassem dinheiro era claramente visível no exemplo dos Estados Unidos. Porque as ondas da rádio podem viajar para além das fronteiras nacionais, um número de empresários configurou estações de rádio fora do Reino Unido, que irradiaram programas para o país, sem a necessidade de requerimento ou permissão para transmitir ou para se adequar ao planeamento das frequências do governo britânico. Eles tinham permissão para emitir a partir de França, Luxemburgo, Países Baixos e Irlanda, e não precisavam de permissão do governo do Reino Unido. Poste Parisien, Rádio Normandia, Rádio Côte D’Azur, Rádio Lyon e até mesmo as emissoras do Estado em Hilversum, Holanda e Athlone, Irlanda estavam entre as mais populares para transmitir programação patrocinada e anúncios em Inglês, voltadas para o mercado do Reino Unido nos tardios anos 1920 e 1930. A mais duradoura e mais famosa delas foi a Rádio Luxembourg, que foi forçada a sair do ar durante a guerra, quando o Estado independente do Luxemburgo foi invadido, mas voltou para as ondas hertzianas assim que terminaram as hostilidades, emitindo até meados da década de 1990. Por esta altura a BBC tinha desenvolvido os seus três serviços nacionais de rádio, o Light Programme, o Home Service e o Third Programme. O último era uma rede cultural, que emitia música clássica e programas de debate; o Home Service oferecia aos ouvintes uma dieta mista, que incluía drama, 
documentários e actualidades, enquanto o Light Programme tinha sido introduzido em 1945 em resposta à reivindicação de um serviço de entretenimento popular que deu provas quando os civis sintonizaram em grande número um serviço temporário de guerra, o Forces Programme. A revolução do rock and roll, porém, tinha em grande parte deixado a BBC para trás, uma vez que a música popular transmitida no Light Programme se caracterizava principalmente por ser 'middle of the road': incluía crooners, grupos de jazz, swing e actos de light orchestra altamente caracterizados; a música dos tops era mais para ser emitida em versões rearranjadas do que na forma original pelos artistas originais. Oficialmente, ainda que não na prática, o monopólio da $\mathrm{BBC}$ permaneceu intacto. Como Milland (2004: 76) sugere, "num tempo em que a televisão se foi tornando o meio dominante na vida britânica, secções da elite governante, que estavam em competição, uniram-se para garantir que a radiodifusão na Grã-Bretanha continuava a reflectir os valores das classes média e alta, e a resistir ao comercialismo tipo americano». Esta é uma noção que era precisamente um primeiro reconhecimento de alguns dos aspectos mais nocivos da globalização cultural por oposição à globalização económica.

Em 1964, um jovem empresário irlandês, Ronan O’Rahilly, decidiu criar a sua própria estação de rádio para Londres e para o Sudeste da Inglaterra, emitindo a partir de um navio fora do alcance das autoridades britânicas. Este, e os acontecimentos que se seguiram, tornaram-se no mais eficaz desafio para o monopólio da BBC rádio. Outro empresário, Alan Crawford, estava a trabalhar num projecto similar. Ambos escolheram ancorar os seus navios no estuário do Tamisa, mas foi a rádio de O’Rahilly de Caroline que defrontou a Rádio Atlanta, lançando programas completos no domingo de Páscoa e ganhando o máximo de publicidade por ser a primeira a oferecer à maioria do público britânico uma estação que passava música ao longo de todo o dia (all-day music station). Mais estações apareceram, algumas mais locais outras mais regionais em termos de cobertura. O governo trabalhista reagiu tentando banir o offshore da transmissão de rádio para o Reino Unido com a Lei Marine Broadcasting (Offenses) de 1967.

\section{Rádio local, pública e privada}

Embora muitos dos comentários se concentrem na forma como os piratas provocaram mudanças na $\mathrm{BBC}$ rádio nacional e introduziram um serviço de música pop para a juventude, a Radio 1 (Fleming, 2002: 32; Wilby e Conroy, 1994: 19), a noção de que existe uma relação de causa-efeito entre a chegada dos piratas e o nascimento da rádio local é bem fundamentada (Crisell, 1994: 33). A primeira estação de rádio local da BBC foi lançada no dia 8 de Novembro de 1967. Inicialmente haveria oito estações, de que a BBC Radio Leicester foi a primeira, mas a rede cresceu para vinte até ao final de 1973 e para quarenta durante a década de 1990. Mais uma vez, era o Estado a fornecer o que iria ser invocado para satisfazer a procura do público. A escolha deveria ser entre os serviços, e não entre os prestadores, e a intenção era que o monopólio de radiodifusão da BBC no Reino Unido fosse totalmente restaurado - com, claro está, a pequena excepção 
da presença contínua da Rádio Luxembourg naquilo que se tinha tornado bem estabelecido como o gueto nocturno menos significativo. No entanto, na campanha para as eleições gerais de 1970, o Partido Conservador prometeu estabelecer a "empresa privada de rádio local" - uma rede de sessenta estações, trazendo a radiodifusão local para o que se descrevia como “comunidades locais". Os anteriores receios relativamente à anarquia das ondas de rádio e a uma repartição na administração ordenada do recurso escasso que é a radiodifusão seriam evitados através da regulação rígida dos conteúdos e da propriedade. Isso seria assegurado por uma nova autoridade, a Independent Broadcasting Authority (IBA). Foram concedidas frequências a termo fixo com base numa avaliação de todas as empresas privadas que se candidatavam. A IBA identificaria uma área a ser servida por um concessionário de rádio local independente, anunciava a oportunidade com um prazo fixo para a recepção de candidaturas e, em seguida, definia um processo de decisão sobre que candidaturas seriam aceites. Havia numerosos critérios aplicados pela IBA para fazer a selecção, e os grupos candidatos tinham que tentar adivinhar quais os critérios possíveis que seriam potencialmente mais cruciais, e garantir da melhor forma possível que corresponderiam a esses critérios. Alguns critérios eram fundamentais: entre eles, a boa gestão do som e credibilidade financeira, para garantir que os rendimentos cobriam as despesas e geravam pelo menos um lucro modesto. Mike Baron comentou que, se algumas das estações pequenas fechassem devido a perdas esmagadoras, isso «teria repercussões graves para toda a rede» (1975: 163). Tal equilíbrio entre receitas e despesas seria mais precário nas obrigações de serviço público que se esperariam das estações, sobretudo porque produzir um discurso de "qualidade" é mais intensivo em recursos do que simplesmente emitir gravações.

Não surpreendentemente, era nessas obrigações de serviço público que os candidatos e a IBA deveriam focar-se com muito cuidado: a programação discursiva, incluindo a actualidade, deveria ser um elemento importante neste processo, mesmo se misturada com a música, a fim de torná-la mais agradável - e mais atraente - para o público. O maior benefício na programação seria, inevitavelmente, o fornecimento de notícias locais. Outra fonte de afinidade e distinção na programação residia na emissão de música especializada, normalmente fora dos horários nobres, longe da programação musical mainstream diurna. Programas cobrindo as artes em geral ou alguma sub-secção, como os livros ou o teatro, eram populares entre os primeiros programadores das rádios locais independentes. Em vários casos, as equipas de informação produziam sínteses das notícias ou da actualidade da semana nas várias áreas editoriais. Também era comum um sumário desportivo à sexta-feira ou ao fim-de-semana. Swansea Sound assumiu o compromisso de emitir programação em galês, e a sua agenda incluia oito minutos de galês às 06:00 de segunda a sábado, meia hora aos domingos e noventa minutos todas as noites. Havia também lições diárias de galês para falantes de inglês. Uma das programações mais imaginativas era da Radio City, em Liverpool, e incluía comédia original escrita por Alan Bleasdale e Gorman John de Scaffold. Havia também um programa semanal de feedback dos ouvintes. Algumas estações experimentaram fórmulas primitivas do que na época estava a tornar-se conhecido como "acesso" à programação, em que os indivíduos ou grupos de pessoas com interesses comuns eram incentivados a fazer a sua própria 
programação original. Para muitos grupos, as crianças não eram apenas uma questão de embelezamento, mas eram também uma decisão natural de fazer parte da programação construída especialmente para os ouvintes mais jovens. Tentava-se programar algo para todos na área local. Uma análise sistemática da programação da época revela uma série de elementos de programação que eram comuns em muitas estações, e muitos outros casos em que estações individuais inovariam, levando as suas próprias identidades locais a ter em conta os seus produtos (Starkey 2011).

Nomear os operadores de rádios locais independentes [Independent Local Radios - ILR] da primeira fase e conseguir as primeiras dezanove estações no ar foi problemático, uma vez que algumas tiveram dificuldades em angariar o capital necessário. As duas primeiras estações lançadas em Londres, em 1973, foram a LBC, estação de palavra, e a Capital, estação de 'entretenimento geral'. O número dezanove não foi intencional, mas as rádios locais independentes quase imediatamente se tornaram vítimas de uma mudança de governo ainda em 1974, quando os trabalhistas voltaram ao poder e suspenderam a expansão da rede (Baron, 1975: 160-6). Esta foi uma verdadeira batalha de ideologias travada na rádio local. Infelizmente, poucas estações registavam lucros nos seus primeiros anos de actividade. Um problema significativo, para além da difícil conjuntura económica dos anos 1970, foi que, ao contrário dos Estados Unidos e de muitos outros países onde a rádio comercial tinha sido autorizada a desenvolver-se mais cedo, a rádio não estava simplesmente no radar de muitos dos mais importantes compradores de meios de comunicação com orçamentos de publicidade para gastar. A rádio era, para eles, um meio não familiar para colocação de publicidade, apesar do recente e breve florescimento das estações marítimas piratas e o exemplo mais durável , mas essencialmente periférico, da Rádio Luxembourg. Além disso, mesmo quando a rede de rádios locais independentes começou a estender-se por todo o país, um punhado de estações equivalia apenas a uma cobertura muito irregular do Reino Unido. Quando a rede foi restrita às primeiras dezanove estações, menos de um terço do número inicialmente proposto, ficou claro que as rádios locais independentes simplesmente não poderiam distribuir uma audiência nacional: o que significou que até aos anos 1990, o share da rádio no mercado total de publicidade do Reino Unido se esforçou por chegar aos dois por cento. Se no seu primeiro ano de actividade, 1974-75, a Greater Manchester Independent Radio (chamada Piccadilly on air) teve um lucro modesto, muitas outras estações não tiveram qualquer lucro. A LBC teve os custos associados ao funcionamento de um serviço de notícias nacional e internacional para uma rede incompleta, uma vez que levou anos a desenvolver uma massa crítica de outras estações de rádio locais independentes para subscrever esse serviço, uma massa suficientemente grande para cobrir os custos totais das suas aspirações. As estações pagavam à LBC vinte libras por cada mil ouvintes, o que representava uma fonte de rendimento insuficiente para fazer o serviço funcionar 24 horas por dia, sete dias por semana, como algumas estações precisavam, e que era, afinal, um dos elementos essenciais de uma rede com claras obrigações de serviço público. 


\section{Flexibilização da regulação - e início da homogeneização}

Felizmente para as rádios locais independentes, os conservadores recuperaram o poder nas eleições gerais de 1979 e iniciou-se a conclusão da rede. Com a era Thatcher chegou a supremacia da direita e depois uma década de desregulamentação da rádio comercial. A política britânica tornou-se mais polarizada, uma vez que os ideólogos conservadores de direita se tornaram mais poderosos. Em 1984 foram atribuídas cinquenta licenças de rádios locais independentes, que estavam no ar ou em vias de lançamento. Tony Stoller descreve os meados dos anos 1980 como um período de relativa estabilidade, durante o qual um número de estações foi financeiramente bem-sucedido, mesmo com o imperativo de cumprir obrigações de serviço público para as suas comunidades locais (2010: 124-5). No entanto, na sua história detalhada da rádio independente, Sounds of your life, Stoller identifica uma reunião da Associação dos Adjudicatários de Rádio Independente [Association of Independent Radio Contractors], em 23 de Junho de 1984, como fundamental para o desenvolvimento do sector desde os seus primórdios como rádios locais independentes até algo bastante diferente: a indústria de rádio comercial de hoje (2010: 144-53). A conferência, que se realizou no Sheraton Skyline Hotel no aeroporto de Heathrow, tornou nítido um mal-estar entre os presidentes e directores das empresas de rádio local independente existentes, o que se veio a revelar um agente catalisador de mudança. Entre as suas principais preocupações estava a renovada discussão em torno da legislação para estabelecer um serviço de Rádio Nacional Independente [Independent National Radio - INR], muito diferente daquele da década de 1970; acreditava-se agora que qualquer rádio nacional independente credível implicaria inevitavelmente o aumento da concorrência pela publicidade nacional. Também se suspeitava que, melhorando as receitas nas rádios locais independentes, a receita obtida podia ser usada para financiar o lançamento da rádio nacional independente. As estações mais bem sucedidas financeiramente na rede de rádios locais independentes já estavam a apoiar as menos bem-sucedidas, através de um sistema de receitas "secundárias" pagas à IBA, uma vez que determinados limiares foram cruzados em termos de lucro, e a IBA, por sua vez, estava a redistribuir estes rendimentos "pelos interesses do sistema como um todo» (Stoller 2010: 38). Enquanto isso, o duopólio estava a ser externamente desafiado por um número de piratas ao largo, que tinha continuado a transmissão em violação da Lei Marine Offences de 1967, e uma recém-chegada, a Laser 558, estava a tornar-se particularmente popular com audiências no Sudeste da Inglaterra.

Em resposta a isto e a uma série de outros factores contextuais, em 1990, a IBA foi substituída pela Autoridade da Rádio que passou a ser o regulador para o Reino Unido da rádio comercial. Com o novo regime, a regulamentação dos conteúdos e da propriedade tornou-se cada vez mais branda. Um dos motivos para sacrificar o sentido de localidade em prol da estabilidade financeira foi criado na esteira da primeira falência real de uma estação: a Centre Radio, na cidade de Leicester, ironicamente o berço da BBC Local Radio, deu o primeiro sinal de morte ao sentido de localidade nas rádios locais independentes. Outras estações tinham dificuldades financeiras, a CBC em Cardiff e a Radio Aire em Leeds, entre outras; mas, se outras foram resgatadas, a 8 de Outubro a Centre Radio foi autorizada a entrar em colapso depois de apenas dois anos no ar. 
Apesar de rapidamente se ter encontrado um novo adjudicatário, a Leicester Sound, tais acontecimentos pouco fizeram para melhorar a reputação da IBA ou da rádio local independente como conceito; e porque a intenção era agora continuar a fazer crescer a rede, muitos fracassos espectaculares assustariam inevitavelmente potenciais investidores e ameaçariam o crescimento futuro. O accionista maioritário da Leicester Sound aproximou-se da Radio Trent em Nottingham, com quem a nova estação compartilhava doze horas por dia de programação de horas mortas, bem como produção, administração, contabilidade e gestão. Stoller sugere que «tais aquisições quase secretas começaram a ser rotina na década de 1980» (2010: 124). Inevitavelmente, porque correu em paralelo com a contínua expansão da rede, a tendência para fusões e aquisições tornou-se imparável. A mais significativa foi, talvez, a da Radio West em Bristol pela sua vizinha próxima, a Wiltshire Radio (GWR), em Swindon, no início de 1985 . Na Wiltshire Radio, Ralph Bernard desenvolveu um apetite pela expansão (que logo pareceu insaciável), estimulado pela nova Lei da Transmissão de 1996, que procedeu a uma ampla revisão da lei sobre a propriedade cross-media (Kuhn 2007: 96). Até Março de 2001 a GWR detinha e controlava um total de 47 estações em todo o Reino Unido. A GWR não estava sozinha na vontade de explorar sinergias de gestão e controlo para trazer economias de escala para uma cada vez maior audiência potencial, e esse foi o motivo da flexibilização das regras na propriedade cross-media na Lei de 1996: fortalecer as empresas de média a fim de aumentar a sua robustez e a sua capacidade para resistir às tempestades económicas.

Consequentemente, um número de outros grupos desenvolveu-se, cada um adquirindo controlo de estações por todo o país, uma vez que estas se tornaram dispostas ou vulneráveis à aquisição. Menos surpreendente do que a dominação do mercado por uma empresa que começou a vida como uma estação semi-rural localizada no mundo rural de Wiltshire foi o crescimento da Capital Radio de Londres num grupo totalmente separado. Em resumo, a ladainha de aquisições e fusões, aquisições e manobras que inevitavelmente também aceleraram ao longo dos anos 1990 e 2000 é mais um caso de estudo nas disciplinas associadas de economia e gestão do que uma grande preocupação para a nossa análise. Ainda assim, é importante notar que o frenesim em que se desenvolveram foi profundamente prejudicial para o sentido de localidade na propriedade e na geração de conteúdos que temos vindo a considerar. Dito cruamente, em muitos casos o que antes eram estações de propriedade e gestão local nas quais as decisões sobre os conteúdos locais eram tomadas localmente, tornou-se mera engrenagem em operações muito maiores que viram os processos de homogeneização como progresso. Em 2003 uma nova Lei das Comunicações trouxe um novo regulador, o Ofcom, e uma abordagem ainda mais leve relativamente à regulação dos conteúdos e da propriedade. O ritmo de homogeneização da produção da rádio local acelerou desde então. Crucial foi o desenvolvimento da tecnologia de armazenamento digital e reprodução, e com ele a maior facilidade de programação automática e dos programas em cadeia em várias estações ao mesmo tempo, incorporando notícias e publicidade local na programação transmitida para públicos em muitas comunidades diferentes. Outra forma relativamente nova em que grandes grupos de rádio podem explorar economias de escala, a fim 
de tornar o seu negócio mais rentável, é a co-localização, onde duas ou mais estações poderiam realmente transmitir a partir do mesmo estúdio, mesmo estando fora da área para onde estão a transmitir.

\section{Rádio local, a caminho do global}

A propriedade é muitas vezes difícil de descrever no presente apenas porque o controlo pode mudar da noite para o dia, e os activos não são negociados por causa da regulação da concorrência, mas podem ser vendidos ou simplesmente trocados entre os grupos existentes e emergentes meramente por uma questão de conveniência, por exemplo, a fim de racionalizar as operações em torno de uma área geográfica. O retrato da propriedade representado pela Tabela 1 não é incontestável, mas serve como indicação útil da relação entre os principais intervenientes no sector da rádio comercial do Reino Unido e aqueles com interesses menores. Mesmo aqueles grupos com menores participações são agentes importantes na paisagem mediática onde detêm ou operam estações, e outros factores podem complicar as coisas. O UKRD [UK Radio Developments], por exemplo, possuía e tinha uma participação na Eagle Radio and County Sound (Guildford), KL.FM (King's Lynn), Cambridge Star e Pirate FM (Redruth), mas também possuía um terço da Heart (South Hampshire) e um terço da Nova (Weston-Super-Mare). Porque o UKRD também possuía acções suficientes em The Local Radio Company Group (TLRC), também tinha o controle efectivo da Mix 96 (Aylesbury), Spire FM (Salisbury), Wessex FM (Dorchester), Spirit FM (Chichester), 2BR (Burnley), Minster FM (York), FM Stray (Harrogate), as duas licenças da Yorkshire Coast Radio em Scarborough e Bridlington, Sun FM (Sunderland) e um conjunto de três estações em Darlington, Durham e Northallerton, todas agora usando uma das marcas favoritas do UKRD, Star. Através do TLRC, o UKRD ainda controlava um terço da Bee (Blackburn).

Neste microcosmo da nova complexidade na propriedade e controlo das estações, encontram-se alguns exemplos interessantes de como a flexibilização da regulação representada pela Lei das Comunicações e sua interpretação pelo Ofcom tem sido explorada pelos grupos de rádio menos controlados localmente para aumentar o lucro das estações individuais. Dito sem rodeios, isto pode parecer ser intencionalmente pejorativo, mas é importante reconhecer que muitas das estações de que estamos a falar estão localizadas em áreas tão pequenas ou pouco povoadas, que não teriam sequer sido contempladas como áreas potencialmente viáveis para o desenvolvimento de uma estação de rádio local independente, uma vez que a rede foi originalmente concebida no espírito do 'amanhã melhor' dos conservadores. Se um número de estações locais independentes da primeira fase com áreas muito maiores se esforçou tanto por angariar capital de lançamento como para se manter viável durante as crises económicas, dificilmente seria surpreendente que estações mais pequenas se esforçassem até com lucros financeiros trazidos pela tecnologia digital. Vistos mais positivamente, o UKRD e o TLRC são grupos que se esforçaram por ganhar licenças e lançar estações, quando algumas das mais pequenas áreas eram anunciadas pela Autoridade da Rádio e pelo Ofcom. Seja pelas suas próprias falhas ou pela mão económica, estes e outros gru- 


\section{Tabela 1}

A relativa complexidade dos principais grupos de rádio comercial do Reino Unido (excluindo os grupos/estações exclusivamente digitais, como a Planet Rock e a UCB) em Janeiro de 2011, de acordo com as licenças analógicas e emissoras nacionais a operar (se disponíveis através de meios analógicos ou apenas digitais).

\begin{tabular}{|c|c|c|}
\hline \multicolumn{2}{|c|}{$\begin{array}{l}\text { Número de licenças de rádio comercial } \\
\text { analógica atribuídas }\end{array}$} & $\begin{array}{c}\text { Marcas nacionais de rádio analógicas e digitais } \\
\text { que operavam }\end{array}$ \\
\hline Global & $\begin{array}{l}47 \text { FM (includindo } \\
\text { Classic FM), } 23 \\
\text { AM }\end{array}$ & $\begin{array}{l}\text { The Arrow, Choice, Classic FM, Galaxy, } \\
\text { Gold, Heart, LBC, XFM }\end{array}$ \\
\hline Bauer & $24 \mathrm{FM}, 13 \mathrm{AM}$ & $\begin{array}{l}\text { Heat, The Hits, Kerrang, Kiss, Magic, } \\
\text { Q Radio, Smash Hits }\end{array}$ \\
\hline GMG & $13 \mathrm{FM}$ & Real, Smooth \\
\hline UTV & $\begin{array}{l}11 \mathrm{FM}, 4 \text { AM } \\
\text { (includindo } \\
\text { TalkSport) }\end{array}$ & TalkSport \\
\hline Absolute Radio & $\begin{array}{l}1 \text { AM (Absolute } \\
\text { Radio) }\end{array}$ & $\begin{array}{l}\text { Absolute Radio, Absolute 80s, Absolute } \\
\text { Radio 90s, Absolute Radio Classic Rock, } \\
\text { Absolute Radio Extra }\end{array}$ \\
\hline $\begin{array}{l}\text { The Local Radio } \\
\text { Company Group } \\
\text { (controlada pelo UKRD) }\end{array}$ & $13 \mathrm{FM}$ & \\
\hline Lincs FM & $9 \mathrm{FM}$ & \\
\hline UKRD & 4 FM, 1 AM & \\
\hline Sunrise Group & 4 FM, 3 AM & $\begin{array}{l}\text { Sunrise Radio, Kismat Radio, Punjabi } \\
\text { Radio }\end{array}$ \\
\hline Tindle Radio & 9 FM & \\
\hline $\begin{array}{l}\text { Town \& Country } \\
\text { Broadcasting }\end{array}$ & 7 FM & \\
\hline Quidem & $6 \mathrm{FM}$ & \\
\hline KMFM & 7 FM & \\
\hline Orion & $5 \mathrm{FM}, 3 \mathrm{AM}$ & \\
\hline CN Group & 3 FM & \\
\hline
\end{tabular}


pos têm experimentado dificuldades reais para manter os seus negócios nos termos da licença original. Espectacularmente, em 2006 o UKRD devolveu ao Ofcom a licença que tentava operar como Star 107,9 em Stroud, Gloucestershire, ao invés de vendê-la a outro operador, em grande parte para forçar uma resposta do regulador. O presidente-executivo do UKRD, William Rogers, exigiu «um debate sério e significativo na indústria para ajudar as estações pequenas a trabalhar e tornar-se comercialmente bem sucedidas». E acrescentou: «Há dezenas de estações de rádio a perder dinheiro que nunca irão funcionar e o regulador tem que olhar seriamente para o modo como deve gerir o sector. Teria sido quase antiético vender a licença, não é uma empresa de som e nunca teria sido. A indústria tem que acordar. Enquanto as pessoas continuarem a comprar e a vender estes activos deficitários, nunca conseguiremos a mudança que precisamos de ver» (Day 2006). A estação tinha-se lançado como The Falcon, em 1998, e fora posteriormente comprada pelo UKRD e renomeada Star, sendo a estação vizinha que o grupo detinha na maior cidade de Cheltenham. A fim de fazer poupanças nos custos de funcionamento da estação Stroud, o UKRD já tinha pedido ao Ofcom permissão para co-localizar as duas estações, para que o serviço Stroud viesse na verdade de um segundo estúdio em Cheltenham. Como a co-localização era apenas um termo relativamente novo para uma prática que já existia desde a década de 1980, onde a permissão para proceder assim tinha sido concedida pelo órgão regulador da altura, o Ofcom concordou que se tratava de um negócio atraente para o permitir. No entanto, o Ofcom recusou um pedido do UKRD para alterar o formato da estação de Stroud, neste contexto uma declaração juridicamente vinculativa das obrigações de uma programação da estação, que tinha substituído a "promessa de desempenho". O Ofcom ainda se recusou a permitir o mesmo produto para trasmissão simultânea (simulcast) nas duas estações e exigiu que o serviço Stroud mantivesse a sua identidade separada, mesmo sendo gerido a partir de Cheltenham.

Este foi um momento na história da rádio comercial do Reino Unido tão importante como a conferência de Heathrow. O retorno da licença constituiu a primeira vez que o processo de licenciamento e o papel do regulador como árbitro final do que devia ser transmitido numa área licenciada para rádio comercial tinham sido subvertidos de forma tão espetacular, que foi fundamental para o que desde então o Ofcom tentou acomodar amplamente, muitas vezes com brutais alterações aos acordos de licença, no interesse da manutenção de serviços no ar. Enquanto a co-localização de serviços integrais ou partes dos serviços tinham sido autorizadas com parcimónia pela IBA na década de 1980, um novo conceito de grupos reunindo as suas operações de notícias locais em centros regionais conhecidos como "news hubs" viu ditada a sua morte pela Autoridade da Rádio. O grupo que tinha sido pioneiro, o GWR, abriu experimentalmente com o consentimento da Autoridade um centro principal no Sudoeste de Inglaterra em 2002. O centro começou a servir as estações GWR em Plymouth, Exeter/Torbay, Yeovil \& Taunton, Kingsbridge e Barnstaple pré-gravando cada um dos seus próprios noticiários locais, usando cópia e áudio produzidos remotamente no próprio centro ou por repórteres que trabalhavam nas diferentes TSA que alimentariam o material reunido no centro. Este "agrupamento de recursos", como foi racionalizado, foi permitido na convicção 
de que "a presença jornalística local” seria mantida em cada TSA (Crisell \& Starkey, 1998: 20-21). O Ofcom tomou então o conceito ainda mais longe, focando a sua regulamentação no "conteúdo" em vez de em questões “operacionais", um princípio consagrado no documento, publicado em 2004, Rádio - Preparar o Futuro. Este foi um reconhecimento de que os sucessivos desenvolvimentos tecnológicos e a flexibilização paralela da regulação da propriedade deviam reflectir-se na sua abordagem à regulação de conteúdos. Em 2006, então, com o retorno da licença de Stroud a ameaçar fazer uma paródia da função de licenciamento que tinha sido legada pelo seu antecessor, o instinto inicial do regulador em insistir na letra de cada licença metamorfoseou-se numa insistência apenas no espírito da licença. Isto não significava que o Ofcom se tivesse tornado brando, concedendo cada pedido ou exigência de mudança que recebia. Pelo contrário, os titulares de licença eram ainda obrigados a expor um caso em tribunal e o Ofcom testaria a razoabilidade do que estava a ser proposto antes de decidir cada questão de uma forma ou de outra, e o regulador muitas vezes precisava de ter em mente as implicações possíveis para outros, concessionários concorrentes em áreas de sobreposição, bem como o efeito da mudança sobre a diversidade de opções disponíveis para o ouvinte.

As áreas em que este novo relacionamento foi testado de modo mais controverso incluem alterações de formato, co-localização, centros de notícias e transmissão em cadeia. A transmissão em cadeia foi outro legado da década de 1980 como já vimos, especialmente quando a IBA se mostrava relutante em deixar os recém-chegados à rede produzir a sua própria programação no total das 24 horas diárias de transmissão. A programação durante a noite, menos significativa, devido a níveis de audiência baixos, muitas vezes vinha da programação de centrais (embora o termo não fosse ainda usado desta forma), e em 1986 Beacon (Wolverhampton) fornecia um programa de cinco horas de duração para os seus vizinhos, Mercia (Coventry), Signal (Stoke-on-Trent) e Wyvern (Herefore \& Worcestershire), com apenas intervalos de publicidade separados para distinguir os quatro produtos. Outras iniciativas se seguiram. As estações TLRC já tinham começado a transmissão em simultâneo (simulcasting) dos seus programas da noite em todas as suas estações, enquanto a GWR tinha com sucesso emitido em cadeia Late Night Love with Graham Torrington entre 1996 e 2008 num número de estações que formavam uma submarca chamada The One Network. Tendo sido um dos pioneiros a empurrar o Ofcom ainda mais no sentido que muitos grupos de rádio teriam desejavam, Rogers pode reivindicar algum sucesso, muito embora o prejuízo seja, inevitavelmente, no sentido de localidade. Em primeiro lugar, as três estações no Nordeste de Inglaterra, que tinham sido anunciadas separadamente e ganhado a frequência em Darlington, Durham e Northland, foram originalmente designadas como A1FM, FM Durham e Northallerton Minster, em 1995, 2005 e 2007, respectivamente. Em 2010, após discussões com o Ofcom sobre a possível co-localização mais a norte com a Sun FM em Sunderland, as três estações foram ao invés redesignadas Star e co-localizadas em Darlington. Começaram a transmitir em simultâneo (simulcasting) a mesma programação, sendo a única diferença entre elas a capacidade para difundir separadamente anúncios em cada TSA, mantendo assim a flexibilidade necessária para obter rendimentos de pequenos anunciantes locais ao mesmo tempo que reduziam os 
custos ao máximo mantendo-se no ar. As duas licenças da Yorkshire Coast Radio em Scarborough e Bridlington também transmitiam em simultâneo tudo menos os anúncios locais; entretanto The Bee e a 2BR permanecem serviços separados, sem transmissões nem de Blackburn nem de Burnley, ambas partilhando premissas de co-localização na cidade de Accrington que fica entre as duas.

No primeiro de dois movimentos audaciosos, cujas implicações foram tornadas públicas em 2010, o Global Group estabeleceu primeiro o rebranding de tantas das suas estações quanto possível, da Heart e, em seguida, através de um processo de consolidação, reduziu os custos operacionais da nova marca FM quase nacional ao mínimo que o regulador permitiria. A primeira etapa foi o rebranding em Setembro de 2008 de 29 estações locais como a Heart, maximizando o uso de transmissão em cadeia durante o dia e alargando a marca de sucesso muito além dos seus limites geográficos analógicos originais. Um número de marcas estabelecidas há muito tempo perdeu-se na longa lista dos que desapareceram: 2CR (Bournemouth), 2-TEN FM, Champion, Chiltern (Luton \& Bedford), GWR, Marcher Sound, Gemini, Q103 (Cambridge), Essex FM, Severn Sound, Ocean (Portsmouth e Southampton), Invicta, Lanterna, Coast, Fox (Oxford), Plymouth Sound, Orchard FM, FM Sul (Brighton), The Buzz, SGR (que havia absorvido as duas estações de Suffolk Orwell e Saxon em 1992), Horizon (Milton Keynes), Broadland (Norfolk), Northants 96 e Hereward (Peterborough). Na segunda fase, em Junho de 2010, as 33 estações separadas a operar sob a marca Heart foram agrupadas em quinze 'super-estações' Heart, centralizando o que a produção local manteve em centros de notícias e programação regionais, um movimento que se esperava que causasse a perda de duzentos freelancers e colaboradores. Além disso, as duas estações da Global FM que tinham sido deixadas intactas na primeira fase, Mercurio (Reigate \& Crawley) e RT-17 (Harlow), também foram redesignadas e incorporadas nas duas 'super-estações' Heart. A segunda consolidação dramática da Global foi a fusão em Janeiro de 2011 das seis estações regionais que detém agora na Escócia, em South Coast, Birmingham, Manchester, Yorkshire e Nordeste da Inglaterra com o restante património de rádios locais independentes Red Dragon (Cardiff), Trent, Ram (Derby) e Leicester Sound para estender a marca Capital FM noutra rede quase nacional. Apenas algumas sequências seriam produzidas separadamente nas regiões a partir de Londres, que foram retransmitidas em todas as outras, e com o intuito de preservar alguma distintividade dos apresentadores com sede em Londres que pré-gravariam variações regionais de algumas das suas ligações. Ligeiras variações nas straplines das estações, associando a marca a cada localidade, juntamente com os noticiários locais, trânsito e anúncios de viagem e comerciais, completaram o quebra-cabeças do sentido de localidade que amplamente conheceu o novo foco de regulamentação sobre a produção, ao invés de processo. De acordo com a Global, tratava-se de "rádio local difundida a nível nacional". Com a Heart e a Capital agora quase nacionais em FM e herdando as audiências de todo o país que tinham sido meticulosamente estabelecidas sob um vasto conjunto de diferentes marcas locais, formatos, dados demográficos-alvo e TSA, a Global foi empurrando até ao limite o conceito de sentido de localidade por cuja porta dos fundos a rádio comercial tinha entrado no Reino Unido. 


\section{Que futuro para a rádio local?}

Este foi um triunfo retumbante do comercial sobre o local na medida em que permitiu que uma empresa privada que já detinha uma licença nacional para a Classic FM construísse efectivamente mais duas estações nacionais, embora ainda dependentes de uma manta de retalhos de transmissores de relativamente baixa potência e frequências espalhadas na metade superior da faixa de FM. Considerando que, na medida em que a rádio comercial foi capaz de desafiar a BBC, nas suas primeiras versões ela foi deliberadamente limitada; na primeira versão foi apenas local, e só depois disponível a nível nacional em nichos - até 2011 a Global Radio, pelo menos, estava pronta para competir com a BBC Radio 1 e 2. Em princípio, isso também fazia sentido do ponto de vista comercial, mas era também, em certa medida, uma aposta em ouvintes que não se importavam com a diminuição do sentido de localidade que dela resultava. Porque alguns requisitos permaneceram para o conteúdo local, como as estações individuais Heart na nova rede Capital, também teriam algum material regional encomendado quando apropriado; mas deixar-se-iam os ouvintes enganar? A rádio é realmente um meio inteligente, e muitas das pessoas que nela trabalham são engenhosas na adaptação das suas características inerentes, a fim de as explorar ao máximo. No entanto, as abordagens muito criativas para reconstruir a rádio que a produção digital e a tecnologia de distribuição nos permitem no século XXI não são acríticas. Noutro sentido, no entanto, talvez possamos sentir que isto é apenas ou não, o maior teste de sentido de localidade que a rádio local pode ter no mercado - serviços comerciais e públicos. No caso do sector comercial, os mercados de nicho por vezes abandonados pelos grandes agentes podem ser explorados por recém-chegados, e, como a Global Radio e outras abandonam alguns elementos-chave da rádio local para uma maior consolidação e homogeneização, conceitos como os de comunidade e Internet ou mesmo mais recentes formas de rádio que ainda não imaginámos podem contribuir para preencher o vazio. As rádios comunitárias dependem fortemente do apoio voluntário e podem sustentar pouco pessoal assalariado, mas, se os níveis de profissionalismo puderem ser definidos como elevados e sustentados, ainda se poderá manter o sentido de localidade vivo. O serviço público de rádio também tem que encarar testes, a fim de continuar a atrair financiamento público. A BBC Local Radio continua a servir as comunidades, embora nem sempre as mais populosas, com um serviço em grande parte gerido, produzido e dirigido, se não exactamente a toda a comunidade, certamente, a uma subsecção da mesma. Os desafios que a BBC Local Radio actualmente enfrenta incluem os que são comuns ao resto da BBC. Quando o terceiro mandato do Partido Trabalhista terminou em 2010 e um governo de coligação apoiado por liberais democratas impôs um corte de $16 \%$ no financiamento da BBC, além de remover o financiamento estatal do Serviço Mundial de Rádio, a mudança política do país à direita sinalizou um aperto quase imediato dos orçamentos que seriam necessários. Uma das maneiras mais óbvias de economizar dinheiro na BBC Local Radio é reduzir a quantidade de programação produzida localmente. Em várias ocasiões isso foi conseguido, mais comummente durante a noite, por grupos geográficos de estações reunindo recursos para financiar um programa que é compartilhado por todas elas. Tal tem a vantagem considerável de poder reflectir o gosto numa base regio- 
nal alargada e não estreitamente local. Uma consideração cuidadosa da maneira como estes programas e as estações que os emitem pode evitar a confusão óbvia da afinação inicial de programas de rede que eram completamente insensíveis às estações de rádio locais sintonizando dentro e fora delas. A transmissão simultânea do programa da tarde estava a ser testada, em Abril, em três estações de Yorkshire (Radio Leeds, Radio York e Radio Sheffield) e duas do Sudeste da Inglaterra (Radio Kent e Sussex Radio \& Surrey) (Plunkett 2010). Se for mantida ou mesmo ampliada, esta abordagem para redução de custos será certamente conseguida à custa do sentido de localidade na rádio local. Num clima político mais amplo em que cortes brutais estão a ser feitos para uma ampla gama de serviços públicos - dos conselhos locais para as artes, humanidades e ciências sociais no ensino superior -, seria surpreendente se, com financiamento público, a radiodifusão de serviço público deste tipo não fosse afectada.

Se o futuro da rádio pode muito bem ser brilhante, preservar e estimular o sentido de localidade pode vir a depender inteiramente da vontade dos legisladores e reguladores de o manter vivo. A distinção pode custar quantias desproporcionais de dinheiro, e a preservação do património - cultural e radiofónico - pode exigir esforço e despesas, bem como vontade política. O grande prémio é a expressão e a estimulação da diferença cultural, mas pode escapar das nossas mãos. A regulação da propriedade e do conteúdo, bem como a prestação de apoio financeiro podem todos ser essenciais para evitar que a rádio local se torne global.

\section{Referências bibliográficas}

Baron, M. (1975) Independent Radio, Lavenham: The Lavenham Press.

Briggs, A. (1961) The History of Broadcasting in the United Kingdom: Volume I - The Birth of Broadcasting, Oxford: Oxford University Press.

Crisell, A. (1994) Understanding Radio (2nd edition), London: Routledge.

Crisell, A. \& Starkey, G. (1998) 'News on local radio'. In Franklin, B. (ed.) Local Journalism and Local Media: Making the Local News, London: Routledge.

Day, J. (2006) 'FM licence thrown back at Ofcom', guardian.co.uk, 21th September http://www.guardian. co.uk/media/2006/sep/21/commercialradio.radio1 (acesso em 29/12/10).

Fleming, C. (2002) The Radio Handbook (2nd edition), London: Routledge.

Kuhn, R. (2007) Politics and the Media in Britain, Basingstoke: Palgrave Macmillan.

McCarthy, C. (2007) 'Development of the AM transmitter network', BBC Engineering Information document, London: BBC http://www.mds975.co.uk/Content/bbc_transmitter_development_clive_mccarthy. pdf (acesso em 26/8/10).

McLuhan, M. (2001) Understanding Media: the Extensions of Man, London: Routledge (first published 1964).

Milland, J. (2004) 'Courting Malvolio: The Background to the Pilkington Committee on Broadcasting, 1960-62. In Contemporary British History, Volume 18, Issue 2, pages 76-102.

Starkey, G. (2007) Balance and Bias in Journalism: Representation, Regulation \& Democracy, Basingstoke: Palgrave Macmillan.

Starkey, G. (2011) Local Radio, Going Global, Basingstoke: Palgrave Macmillan.

Stoller, T. (2010) Sounds of Your Life: A History of Independent Radio in the UK, New Barnet: John Libbey Publishing.

Wilby, P. \& Conroy, A. (1994) The Radio Handbook, London: Routledge. 